\title{
Nachtrag zu meiner Arbeit: „Ueber Keratoplastik."
}

Von

Stabsarzt Dr. Selle rbeck*).

$D_{\mathrm{a}}$ sich die Herausgabe dieses Bandes um einige Monate verzögert hat, so benutze ich die Gelegenheit, über den Fall Gartz noch eine kurze Mittheilung zu veröffentlichen.

Im Gebranche des operirten Auges ist G. jetzt völlig unbehindert; er giebt nur an, dass er an windigen Tagen zuweilen an dem Auge ein eigenthümliches Gefübl von Kälte empfinde, welches ihn zwinge, die Lider häufiger als gewöhnlich zu schliessen oder auch wohl für einige Secunden geschlossen zu halten.

*) Nachstehende Mittheilung des Herrn Dr. Sellerbeck ist uns erst zugegangen, nachdem die vorstehende Notiz von Herrn Prof. Schweigger über denselben Gegenstand bereits gedruckt war. Da Herr Dr. Sellerbeck angiebt, von letzterer vorher keine Kenntniss erhalten zu haben und da die von ihm mitgetheilten Untersuchungsresultate, sowie seine ganze Auffassung des Falles von den in der Notiz des Herrn Prof. Schweigger enthaltenen abweichen, so haben wir keinen Anstand genommen, seine Mittheilung hier ebenfalls zu veröffentlichen.

v. Graefe's Arehiv für Ophthalmologie, XXIV. 4.

Die Redaction. 
Die transplantirte Cornea misst gegen $6 \mathrm{Mm}$., sie grenzt sich bei oberflächlicher Betrachtung nur nach aussen oben durch eine geringe Niveandifferenz und eine Aenderung des Farbentones deutlich ab. Die bläulichweisse Randzone der Scheibe umgiebt eine ziemlich central gelegene, nierenförmige Stelle, welche bei Tagesbeleuchtung matt grauschwarz erscheint. Bei seitlicher Beleuchtung und Untersuchung mit der Loupe erweist sich im inneren oberen Quadranten der frühere Leacomsaum jetzt völlig durchsichtig und frei von Gefässen: Man erkennt mit vollster Deutlichkeit die Details der destruirten Iris, welche, von der hinteren Cornealfläche durch humor aqueus abgedrängt, im flachen Bogen vom ciliaren Ansatz zur Operationsnarbe hinzieht und mit derselben verschmilzt. Im Uebrigen ist der Leucomring noch völlig undurcbsichtig und trägt eine grössere Anzahl von radiär verlaufenden Gefässen, welche am Rande der transplantirten Cornealscheibe schlingenförmig umbiegen und nur 2-3 feine Aestchen in dieselbe hineinsenden. Mit Ausnahme der erwähnten Stelle im äusseren oberen Quadranten zieht das Epithel ohne irgend welche erkennbare Differencirung glatt über die Narbe hinweg. Die Grenze des eingeheilten Hornhantstückes ist aber aberall deutlich zu verfolgen, sie markirt sich gegen den undurchsichtig gebliebenen, mässig vaseularisirten Theil des Leucomringes dadurch, dass das transplantirte Gewebe selbst am Rande sich noch eine gewisse Diaphanität (etwa wie Wachs) bewahrt hat und fast gefässlos ist. Der peripherische Theil der Hornbautscheibe zeigt eine ziemlich erhebliche parenchymatöse Trübung, während ein central gelegener Theil nur schwach getrübt ist und gut durchlenchtet werden kann. Durch den weniger getrübten Bezirk sieht man hinter der Cornea ein schmutzig graues Gewebe (vielleicht eine von den Irisresten vorgeschobene Schwartenbildung), welches ziemlich central eine nieren- 
förmige, ophthalmoskopisch nicht erleuchtbare Lücke von etwa $2 \frac{1}{2} \mathrm{Mm}$. freilässt. Das transplantirte Gewebe ist noch insensibel. $\mathrm{T}=\mathrm{n}$. Auf meine Bitte haben die Herren Collegen Brecht, Hirschberg und Schöler, welchen ich $G$. in ihren Polikliniken am 3. December vorführte, die Güte gehabt, eine Sehprüfung vorzunehmen. Her" College Brecht constatirte Abends „bei Lampenbeleuchtung Fingerzählen auf $3^{\prime}$, Buchstaben Snellen (Wandtafeln) 9,0 M. in etwa 5 Cm."; Herr College Hirschberg "an sehr trübem Decembertage Fingerzählen auf 3 ' sicher, Schriftproben Schweigger 18,0 M. in grosser Annäherung"; Herr College Schöler "an trübem Decembertage Fingerzählen in $3^{1} / 2$; Schweigger (Wandtafeln) $12,0 \mathrm{M}$. in grösster Nähe." Die Sehprüfungen ergeben nicht immer ganz gleiches Resultat. Das Auge ermüdet noch leicht, so dass dadurch kleine Differenzen ihre Erklärung finden. Der pp. Gartz ist jetzt im Stande, sich mit Hülfe des rechten Auges, welches vor der Operation nur Handbewegung in nächster Nähe sah, nach Verbinden des linken iridectomirten bei Tage auf nicht zu belebten Strassen zú orientiren. Er sieht die Personen, welche ihm entgegenkommen, auf eine Distanz von 3-5 Schritt je nach der Helligkeit des Tages, ebenso etwaige grössere auf dem Trottoir befindliche Hindernisse, so dass er ihnen zur rechten Zeit ausweichen kann.

Ueber das fernere Geschick des Falles gedenke ich zur geeigneten Zeit weitere Mittheilungen folgen zu lassen.

Bei dieser Gelegenheit möchte ich noch auf die eigenthümliche Veränderung aufmerksam machen, welche der stehen gebliebene Randtheil der alten Hornhaut im Gebiete des inneren oberen Quadranten erlitten hat. Während dieser Theil zur Zeit der Operation - somit 2 Jahre nach der Primär - Erkrankung - noch völlig opak war, begann er im 3. Monat nach der Keratoplastik 
sich etwas aufzuhellen und war bereits am Ende des 4. Monats so durchsichtig, dass man im inneren oberen Sextanten die anliegende destruirte Iris deutlich wahrnehmen konnte. Die Aufhellung hat bis jetzt weitere Fortschritte gemacht, wäbrend zu gleicher Zeit an dieser Stelle die Iris allmählig durch humor aqueus von der hinteren Fläche der aufgeklärten Cornealparthie abgedrängt wurde. Die Verhältnisse liegen hier jetzt so günstig, dass nach einiger Zeit, wenn die Trübung des Cornealfensters, anstatt sich weiter aufzuhellen, gar noch zunehmen sollte, eine Iridectomie mit Aussicht auf leidlichen Erfolg vorgenommen werden könnte. Meine Beobachtung ist übrigens nicht neu. Wie uns v. Hippel*) in seiner Arbeit über Keratoplastik mittheilt, hat bereits Desmarres ähnliche Beobachtungen an Thieren gemacht. und auf Grund derselben die Ansicht ausgesprochen, dass die Transplantation nicht zu dem Zweeke auszuführen sei, dass die überpflanzte Hornhaut (welche einer secundären Trübung anheimfalle) das Sehen wieder ermögliche, sondern in der Absicht, dass der Leucomring in Folge der Dehnung, welche die schrumpfende Hornhautscheibe auf ihn ausübe, seine Transparenz wieder gewinne. Wenn ich auch dieser Ansicht von Desmarres keineswegs beiflichte, den Endzweck der Keratoplastik vielmehr nur darin sehe, dass uns die Einheilung der transplantirten Cornea mit Erhaltung der. Transparenz gelingt, so würde ich es doch immerhin noch als einen Gewinn betrachten, wenn, nach ev. Vernichtung eines primären Erfolges durch äussere Umstände, in einzelnen Fällen ein Theil des Leucomringes in Folge des operativen Eingriffes sich in dem Grade wieder aufklären würde, dass eine ungefährliche Nachoperation noch ein leidliches Sehvermögen wieder herstellen könnte.

*) Archiv XXIII. 2, S. 99. 